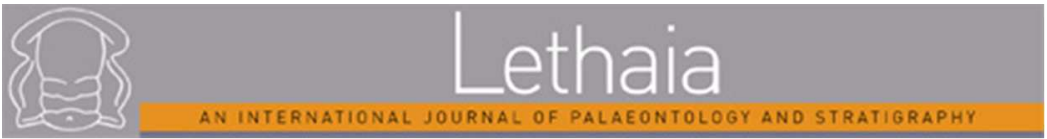

\title{
On the association between increased tooth crown-height and chewing efficiency, and implications for Cervidae evolution
}

\begin{tabular}{|r|l|}
\hline Journal: & Lethaia \\
\hline Manuscript ID: & LET-OA-05-14-0556 \\
\hline Manuscript Type: & Original Article \\
\hline Date Submitted by the Author: & 15 -May-2014 \\
\hline Complete List of Authors: & $\begin{array}{l}\text { DeMiguel, Daniel; Institut Català de Paleontologia Miquel Crusafont, } \\
\text { Neogene and Quaternary faunas } \\
\text { Azanza, Beatriz; Universidad de Zaragoza, Departamento de Ciencias de la } \\
\text { Tierra } \\
\text { Cegoñino, Jose; Centro Politécnico Superior, Departamento de Ingeniería } \\
\text { Mecánica, Área de Mecánica de Medios Continuos y Teoría de Estructuras } \\
\text { Ruíz, Inmaculada; Centro Politécnico Superior, Departamento de Ingeniería } \\
\text { Mecánica, Área de Mecánica de Medios Continuos y Teoría de Estructuras } \\
\text { Morales, Jorge; Museo Nacional de Ciencias Naturales, Departamento de } \\
\text { Paleobiología }\end{array}$ \\
\hline Keywords: & $\begin{array}{l}\text { Fossil ruminants, hypsodonty, evolution, paleoecology, biomechanics, } \\
\text { Finite Element Analysis }\end{array}$ \\
\hline
\end{tabular}




\section{On the association between increased tooth crown-height and chewing efficiency, and implications for Cervidae evolution}

Short title: Tooth crown-height and chewing efficiency

Daniel DeMiguel, Beatriz Azanza, José Cegoñino, Inmaculada Ruiz and Jorge Morales

During the last 20 million years, mammals of numerous lineages have evolved highcrowned (hypsodont) teeth. This major phenotypic change is one of the most widely studied evolutionary phenomena in a broad range of disciplines, though the mechanisms underlying its transformation remain unresolved. Here we present the first experimental Finite-Element Analyses to test the alternative hypothesis that hypsodonty would benefit cervids by increasing the effectiveness of their chewing biomechanics. We found that more hypsodont teeth are suited for restricting stresses to those areas where chewing loading occurs. This important mechanical improvement is consequence of specific and pronounced variations in tooth geometry and morphology of the occlusal surface that are related to crown growth in the vertical plane. We demonstrate that hypsodonty enables selenodont-teeth to adopt a mechanically improved design that increases the pressure whilst shearing foods. As ruminants are unable to digest vegetation directly, hypsodonty is highly advantageous when feeding on mechanicallyresistant fibrous foods. Consequently, it allows grass-eaters to spend less time chewing, thereby increasing the volume of food ingested and/or providing more time for digestion. This study provides a promising line of evidences in support of biomechanical effectiveness as a factor in explaining the evolutionary origins of the hypsodont phenotype. Fossil ruminants; hypsodonty; evolution; paleoecology; biomechanics; Finite Element Analysis.

[Escribir texto] 
Daniel DeMiguel [daniel.demiguel@icp.cat], Institut Català de Paleontologia Miquel Crusafont, Universitat Autònoma de Barcelona, Edifici ICP, Campus de la UAB s/n, 08193 Cerdanyola del Vallès, Barcelona, Spain; Beatriz Azanza [azanza@unizar.es], Departamento de Ciencias de la Tierra, Área de Paleontología, Universidad de Zaragoza. Instituto Universitario de investigación en Ciencias Ambientales de Aragón (IUCA), Pedro Cerbuna 12, 50009 Zaragoza, Spain; José Cegoñino [jcegoni@unizar.es] and Inmaculada Ruiz [iruiz@unizar.es], Departamento de Ingeniería Mecánica, Área de Mecánica de Medios Continuos y Teoría de Estructuras, Centro Politécnico Superior, María de Luna 3, 50018 Zaragoza, Spain; Jorge Morales [mcnm166@mncn.csic.es],Departamento de Paleobiología, Museo Nacional de Ciencias Naturales-CSIC, José Gutiérrez Abascal 2, 28006 Madrid, Spain.

\section{Correspondence}

Daniel DeMiguel, Institut Català de Paleontologia Miquel Crusafont, Universitat Autònoma de Barcelona, Edifici ICP, Campus de la UAB s/n, 08193 Cerdanyola del Vallès, Barcelona, Spain.

E-mail: daniel.demiguel@icp.cat

[Escribir texto] 


\section{Introduction}

\section{Hypsodonty and hypotheses for explaining the increase of tooth crown height}

The development towards a high, or hypsodont, dentition is a fascinating example of evolutionary process among mammals (Osborn 1910; Simpson 1944, 1953; Stirton 1947; White 1959; Fortelius 1985; Janis 1988; Janis \& Fortelius 1988; Williams \& Kay 2001), and one of the best cases of adaptive response to an environmental change. Many grazing mammals (i.e., animals subsisting primarily on grasses, rushes and sedges) of numerous lineages that differ in body size, digestive physiology and dental morphology have independently evolved this phenotype during the last $20 \mathrm{Ma}$ (10). Therefore, increasing hypsodonty can be considered as a response to the challenges posed by feeding on grasses that are associated with changes in habitat structure, particularly with the emergence of open and, generally or seasonally, dry ecosystems (Janis 1988; MacFadden 1997, 2000, Strömberg 2006). Exogenous grit and dust ingested in these ecosystems are considered as another possible selecting force on hypsodonty by leading to increased tooth wear (Janis 1988; Mendoza \& Palmqvist 2007; Jardine et al. 2012).

Most hypotheses consider hypsodonty as an advantage for coping with the excessive rates of dental wear that are associated, but which are by no means restricted, with grassy diets. For an animal with excessive rates of tooth wear, a dentition that is sufficiently durable (or high) will result in an increased life span and reproductive output (Damuth \& Janis 2005; Jordana et al. 2012). Grasses are among the most abrasive, tough and low quality foods that are consumed among ungulates (Lucas 2004). Thus, intracellular abrasives (silica phytoliths) abundant in many grasses (McNaughton et al. 1985; Lucas et al. 2000), higher masticatory efforts as a result of these low-nutritional and mechanically resistant foods (Janis 1976; Axmacher \& Hofmann 1988), and extraneous particles (grit, soil and dust) attached to the grasses in

[Escribir texto] 
open and dry habitats (Janis 1988; Williams \& Kay 2001; Jardine et al. 2012), are often stated as candidates for explaining the increase of wear in tooth, and hence regarded as the evolutionary driver of hypsodonty.

\section{Limited understanding of tooth crown height and incongruities}

Despite this, the issue of this type of dentition is more complex than one might expect (see the electronic supplementary introduction), and there is little conclusive support for any single hypothesis (Williams \& Kay 2001; DeMiguel et al. 2008). Even a hypothesis combining some of the aforementioned reasons could be valid. Also, much of the understanding of hypsodonty is limited by being a feature of specific groups of mammals - typically on equids (MacFadden \& Cerling 1994; Strömberg 2006; Eronen et al. 2010; Mihlbachler et al. 2011) — and because studies are focused largely on time intervals which are not completely coincident with its origins within a group. In ruminants, the development of hypsodonty does not show a clear correspondence with the acquisition of a grazing habit. Only Bovidae and Antilocapridae - mainly represented by species fully adapted to open ecosystems - typically show hypsodont dentitions. Despite this, not all the hypsodont ruminants are grazers, and not all the grass-eaters are similar in their degree of hypsodonty. Exceptions to such correlation include, among others, Antilocapra americana and Eudorcas thomsoni or Nanger granti (Fig. 1A), which exhibit highly hypsodont teeth despite being considered as a browser (animals eating dicotyledonous plants; including leafs, stems, bark, fruits, etc.) and two mixed feeders (animals with composite diets of grasses, rushes and sedges, and browse), respectively. Besides, some extinct bovids comprise forms that are hypsodont while having tooth wear patterns indicative of browsing, such as the Late Miocene Gazella deperdita (Hypsodonty Index (HI) of 3.03; Fig. 1A). Cervids, by contrast, have

[Escribir texto] 
brachydont (i.e., low-crowned) to mesodont (medium-crowned) dentitions (HI from 1.30 to 2.79 ; ref. Janis 1988), and though they display grazing in near water habitats or fresh grass-patched areas, never show diets that are entirely formed of this component. It has been proposed that without the ability to fuse the primary four cusps of the selenodont molar early in ontogeny, cervids are constrained into the formation of wide, low aspect ratio teeth that are suitable only for chewing high quality and low abrasion foods (Heywood 2010). Despite this, the oldest cervids known (Procervulus, Heteroprox and Dicrocerus) show molar wear patterns indicative of high abrasion diets (DeMiguel et al. 2010, 2012), which has led to propose a facultative mixed feeding as the ancestral for Cervidae, as well as the starting point of the evolutionary diversification towards other diets (DeMiguel et al. 2008). Evidence from the paleontological literature reveals that a variety of other contemporaneous herbivorous clades such as giraffids, tragulids, oreodonts and dromomerycids (Franz-Odendaal \& Solounias 2004; Semprebon et al. 2004; Mihlbachler \& Solounias 2006; Ungar et al. 2012) were also brachydont taxa with a strong leaning towards grazing, hereby raising the possibility that mixed feeding may in fact have been the ancestral condition for several artiodactyl families (DeMiguel et al. 2008). Even some of the earliest brachydont equids show dental wear consistent to full grazing (Mihlbachler et al. 2011). For fossil ruminants, the presence of brachydont teeth does not always imply a lack of grass in diet, and therefore a browsing behaviour (Fig. 1A). These results, as many others (see the electronic supplementary introduction), suggest that another factor than grass content in diet seems to be associated with increased hypsodonty.

In order to further explore the coevolutionary link between grass foraging and tooth crown height, we inspect together the evolutionary changes of hypsodonty and feeding style in living ruminants through a molecular phylogeny (Fig. 1B), in where several

[Escribir texto] 
fossil taxa were also included to polarize the characters. Because grazing and hypsodonty evolved independently, we assume tooth wear due to grazing did not influence the development of hypsodont. Cervidae is a good example of a clade that acquired mixed habits although still having non-hypsodont dentitions (see for example living Cervus elaphus, Muntiacus reevesi and Rangifer tarandus and extinct Dicrocerus elegans and Procervulus ginsburgi in Fig. 1B). Contrarily, numerous taxa (e.g., $A$. americana, Hydropotes inermis and Moschus moschiferus) experienced an increased in crown height independent of the grass-eating (Fig. 1B).

A closer inspection of hypsodonty also reveals that it implies something more than a mere increase in height (Eronen et al. 2010). Brachydont teeth coincident with the origins of hypsodonty that are morphologically similar to hypsodont teeth classified as brachydont, while ones that are morphologically dissimilar are classified as mesodont. As such, it should be evaluated, first, if these changes in morphology were a prerequisite for very tall molar crowns, and, second, if were adaptations related to diet or to other component of open habitats. The case of first cervids (Procervulus) and bovids (Eotragus) from the early Miocene of Europe (ca.16 Ma) is intriguing because the hypsodonty indexes classify both species' teeth as brachydont but, morphologically, the bovid teeth are more hypsodont. Interestingly, both genera are of similar body size, but Procervulus exhibits a mixed diet in most of the sites (DeMiguel et al. 2008, 2010) and Eotragus a browser (Solounias \& Moelleken 1994; DeMiguel et al. 2011). As they appear together at the same fossil sites, differences in hypsodonty cannot be explained by environmental dissimilarities. This is of interest for several reasons. First, is why did cervids incorporate large amounts of grass in their diets early in their evolution, despite being brachydont? And second, why did bovid teeth display a tendency towards increased hypsodonty before grazing habits were acquired? All this raises concerns that 
have not been addressed, and suggests that incipient hypsodonty in ruminants was not related to diet.

\section{Testing an alternative hypothesis}

In light of these arguments, and despite being one of the most widely studied evolutionary phenomena and a classic example of adaptation, there are several inconsistencies with the origin of hypsodonty, and many questions concerning its later evolution remain unresolved. Further, the role of its biomechanical performance, which might be linked to the changes in morphology that represent hypsodonty by itself, still remains unexplored, and a mechanical factor could lie behind hypsodonty. Indeed, if cheek teeth are improved for chewing and, consequently, for increasing the efficiency of mastication, it can be predicted that highest-crowned teeth will be most efficient in distributing stress in response to the loads applied when chewing. Here, we are therefore concerned with elucidating the principles that underlie the evolution of hypsodonty through the study of the biomechanical performance of different teeth—some of which are coincident in time to its development. Specifically, we explored if hypsodonty may lead to increase the efficiency and effectiveness by looking at stresses in the tooth.

We inspected our prediction in three different steps. Firstly, we examined and compared the biomechanics of two different 3D-models of brachydont teeth, one belonging to a cervid and other to a bovid, with different morphology (in order to control the role of shape). Secondly, we added to the comparison a third 3D-model of a cervid tooth with higher hypsodonty and different morphology (to control the role of shape plus hypsodonty in a same clade). Finally, we digitally created and added to the comparison a fourth 3D-model of a tooth with higher hypsodonty (similar to that of the third model) but equal morphology to that of the brachydont cervid model (to control 
the role of hypsodonty). The basic assumption underlying all these analyses is that the presence of grass in diet was not a major factor influencing the increase of crown height in cervids, as Cervidae is a good example of a clade that exhibited mixed diets early in its evolution-although still having brachydont dentitions (DeMiguel et al. 2008)-and never has shown exclusively grass diets despite developing mesodont dentitions.

To asses all these comparisons and conduct virtual simulations, we relied on a methodology that would allows us to address a range of questions that have been intractable to date to explore the mechanical and functional effect of increasing the crown height of teeth. This therefore represents the first Finite-Element Analysis (FEA) ever carried out to critically assess how hypsodonty works.

\section{Material and methods}

\section{Hypsodonty estimation}

We measured crown height in fossil taxa according to the index proposed by Janis (1988). HI for lower third unworn molars was determined as $m_{3}$ height divided by $m_{3}$ width. As a result, the term brachydont is restricted to ungulates with an index of less than 1.5; the term mesodont is here applied to ungulates with an index ranging between 1.5 and 3 ; the term hypsodont is applied to those species with an index greater than 3 (and highly hypsodont to species with indices of a greater value than 4.75). Molar HI for extant taxa (Fig. 1) was taken from Janis (1988).

\section{Finite-Element Analysis (FEA)}

In order to inspect if hypsodonty improves the biomechanical efficiency of teeth during the chewing process, we relied on the Finite-Element (FE) method (Zienkiewicz \& Cheung 1967; Zienkiewicz 1971). This technique is potentially one of the most

[Escribir texto] 
powerful tools in the methodological arsenal of vertebrate mechanics, and is commonly applied in biological research to solve problems of biomechanical design in animals (Richmond et al. 2005; Ross 2005; Kupczik et al. 2007; Rayfield et al. 2001; Rayfield 2007; Wroe et al. 2007; Dumont et al. 2009). FE method allows us to recreate stress flows and strain in response to chewing within different teeth and conduct experiments in which models with hypothetical morphologies can be generated through the digital manipulation of real models.

\section{Selection of species and model construction}

Realistic 3D models of ruminant molars were generated using data obtained from scanning the specimens. In order to study the initial development of hypsodonty, we selected two early Miocene pecoran taxa with different dental geometry and diets, with similar tooth crown higher and small/medium body sizes; Procervulus ginsburgi (Cervidae) with a considerable brachydonty and a mixed diet, and Eotragus artenensis (Bovidae) with a relatively incipient hypsodonty (although still brachydont) and a browser feeding. Living Cervus elaphus hispanicus (Cervidae) was included to the study by being different in tooth morphology and more hypsodont - it is in fact one of the Cervidae with higher teeth (Janis 1988) - than P. ginsburgi. Further, C. elaphus is larger sized, exhibits a mixed diet similar to that inferred for the fossil deer, and reaches the same degree of hypsodonty than that of the Middle Miocene bovids, thereby being a very interesting taxon to study the inception and early evolution of hypsodonty. The electronic supplementary figure S1 shows life reconstructions and pictures of all these taxa. Inference of diets were obtained through microwear analyses (DeMiguel et al. 2008, 2011).

[Escribir texto] 
Three $\mathrm{M}^{2}$ s from these taxa from Spain were generated from 3D scans (see Fig. S2 A1) and internal geometry (enamel, dentin and pulp) was determined by micro-CT information (through a Scanco Medical $\mu$ CT 80) (see Fig. S2 A2). Then, data were imported into ABAQUS software. Volumes were meshed creating three-sided (solid tetrahedral and hexahedral) elements (see Fig. S2 A3). The Pg-, Ea- and Ce-models respectively contain the following: $(i)$ Elements $=64,326,46,581$ and 93,426; (ii) Nodes $=38,569,29,874$ and 59,678; (iii) Degrees of freedom $=115,707,89,622$ and 179,034; and $(i v)$ Volume $\left(\mathrm{mm}^{3}\right)=512.5,372.7$ and 3,168. Our FE study includes $(i)$ high resolution models with detailed and complex external geometry, (ii) enamel, dentin and pulp regions being differentiated to obtain more realistically simulate mechanical behaviour, (iii) comparisons beyond two-taxon, which is not frequent in comparative FE analyses, and (iv) digital manipulation to explore the mechanical and functional effect of increasing tooth crown height.

\section{Material properties, constraints and loading conditions}

The models were given an elastic modulus of 50.14 and $10.67 \mathrm{GPa}$ respectively for enamel and dentine, and a Poisson's ratio of 0.3 (typical values for bovine teeth regions, as no data are available for deer dentition; see Lin \& Douglas 1994). We also assigned the models average values of $2 \mathrm{GPa}$ (Young's modulus) and 0.33 (Poisson's ratio) for the tissues filling the pulp chamber (Anusavice \& Tsai 1997). Ruminant upper molars are four-rooted ensuring stability under load. In order to obtain more realistic patterns of stress and strains in the models, dental crowns were attached on the base creating reaction forces representing the manner in which the roots are housed at the alveolar processes of the maxillar and attached to this bone by the periodontal ligament and the gingival that overlies it (see Fig. S2 B1). Highly hypsodont ruminants have molars in

[Escribir texto] 
which the full crown is not visible above the gum line at eruption, thus increasing the insertion and fixation into the bone (Janis 1988), but this is not the case of the specimens here studied.

Major forces for fracturing foods in ruminants comes from the lower jaw movements which load food between the upper and lower teeth thus providing a grinding action to break the food; and there is information about this issue in the literature. Unfortunately, by acting passively, there is very few good data on ruminants with regard to upper teeth movement during the power stroke of chewing and direction of the loads that act.

Hence, observations on the maxillar and the mandible of the taxa here studied were carried out in order to explore what areas of the upper second molars come into contact with the lower molars, and consequently with the food items, during vertical (occlusion stroke) and lateral (grinding) movements. Additionally, and because the orientation of striation patterns on the surfaces of the teeth have proved valuable in tracing the direction of mastication (Lucas 2004; Hautier et al. 2010), we undertook studies of molar microwear on specimens belonging to $P$. ginsburgi, E. artenensis and C. elaphus.

Thus, such direct information obtained allowed us to apply the following two set of forces in the appropriated areas and in the correct direction (see Fig. S2 B). First, a set of vertically (compressive) oriented forces was applied along the crests of the four dental cones to simulate the bite action, and, second, a set of horizontally (lateral) oriented forces was then used to simulate lateromedial jaw movement while chewing in those areas in where the initial wear was observed, and following a vector corresponding to the orientation of the lateral microwear scratches.

In the absence of quantitative estimates of chewing forces for ruminants, we applied a total and arbitrary initial bite force of $694,6 \mathrm{~N}$ for comparative purposes, as used in previous FE simulations (Thomason 1991; Rayfield et al. 2001). Although this force

[Escribir texto] 
does not correspond numerically with our cases, the results were not affected by this premise because we realize qualitative linear-elastic solves. Despite this simplification in the method, linear-elasticity predictions have shown good agreement with experimental data and are useful to conduct stress analysis. Since the constitutive stressstrain relations are restricted to be linear when all other variables are held constant, changing the absolute magnitude of the applied loads would not change the predicted relative distribution of stress in our models (Dumont et al. 2009). However, and given that we compare stress distribution in teeth that differ in size, such variation will certainly affect magnitude. To account for this and control the effects of size, we scaled forces by volume to the two-thirds power, as described in Strait et al. $(2009,2010)$. This means that the results can be directly compared, and then any differences in the stress and strain fields between the models can be attributed exclusively to the differences in the shapes of the teeth. Von Mises stresses and strains were then calculated for each element in all three models and compared between models.

\section{Experimental FE study}

We conducted a comparative analysis to investigate the exclusive influence of hypsodonty on tooth biomechanics. In order to increase the crown height of the Pgmodel in the vertical plane without causing variation in morphology, neither the upper regions of the cusps nor the lower regions of the base of the valleys were modified. Once the area from which the increase in height occurred was selected, the model was displaced (see Fig. S2 C1) and new slices of elements were manually generated according to the original morphology (see Fig. S2 C2, C3). This model with higher hypsodonty and equal crown geometry resulted in 76.816 elements; 53.727 nodes;

[Escribir texto] 
161.181 degrees of freedom; and $731.8 \mathrm{~mm}^{3}$ of volume. Von Mises and strains were calculated for this theoretical model and results compared between models.

\section{Results}

Comparison between the behavior of the Procervulus ginsburgi (Pg), Eotragus

artenensis $(\mathrm{Ea})$ and Cervus elaphus $(\mathrm{Ce})$ models indicates that there is a very significant difference in the patterns of stress distribution (Fig. 2 right) and strains (see Fig. S3), and also in the values that were obtained. Species show the following values of hypsodonty: HI Pg=0.99 (22); HI Ea=1.23 (this study); and HI Ce=2.11 (Janis 1988).

\section{Von Mises stress during dental compression and grinding}

We found that under vertically directed loads (Fig. 2 A), von Mises stress flows in the Pg-model are extensively distributed through the tooth (Fig. 2 A1). Mean stresses are detected along the crests, and in the central part of the main buccal cuspids (paracone and metacone), and reach from $1.09 \times 10^{5}$ to $1.27 \times 10^{5} \mathrm{kPa}$. The Ea-model (Fig. 2 A2) is mechanically very different to the Pg-model. The stress it carries (from $1.39 \times 10^{5}$ to $1.62 \times 10^{5} \mathrm{kPa}$ ) differs in magnitude from the Pg-model, and the results show fundamental differences in distribution. Although there is a relatively faint concentration in the base of the paracone and metacone, stresses generated by chewing loads are not transmitted far and appear to be mainly concentrated in the buccal and lingual crests. In contrast to the Pg-model, none of the central areas of the cones are affected. The mechanical behavior exhibited by the Ce-model (Fig. 2 A3) largely differs from that seen in both the Pg- and Ea-models. Areas of stress (from $3.00 \times 10^{5}$ to $4.49 \times 10^{5} \mathrm{kPa}$ ) are strictly restricted to the dental crests, and only to the occlusal regions. There are no stresses in either the central part of the dental cones or in the base. Under

[Escribir texto] 
laterally oriented forces (Fig. 2 B), qualitative patterns for all load cases are similar to those mentioned above, though some subtle differences can be observed for the Pg-, and, to a lesser extent, for the Ea-model. More importantly, simulations do again account for large differences between models. Mean stress in the models is also close to the values under compressive loads, subtly higher for both the Pg- and the Ea-model, and slightly lower for the Ce-model. Here, stress in the Pg-model (Fig. 2 B1) is more evenly distributed between the lingual cones (protocone and metaconule), specifically in the inferior margin and areas close to the medial valley. Laterally oriented forces also resulted in higher and more extensive stress along the strongly developed pillar of its paracone. More minor differences are found in the Ea-model (Fig. 2 B2), and its behaviour differs only in that the distribution and magnitude of stress is slightly higher in both the base of the paracone and the central part of the metacone. The difference between the two loading regimes is extremely small for the Ce-model (Fig. 2 B3).

\section{Main strains during dental compression and grinding.}

Models also behave differently in the patterns of strains they show during normal occlusion (see Fig. S3 A). Strains are especially high at the buccal cuspids of the Pgmodel (see Fig. S2 A1), which is particularly notable in the apex of the paracone. In contrast, the buccal crests in the Ea-model carry greater strains than the apices (see Fig. S3 A2), which suggests that there is a tendency towards strain restriction in the crests if an animal has more hypsodont teeth. This pattern is more evident in the Ce-model (see Fig. S3 A3). Here, the principal strains (those represented by warm colors; mainly yellow and green) are not only smaller but have also disappeared from the central part of the dental cones and are mostly restricted to the crests. The strain magnitude is greater for the models under laterally oriented forces (see Fig. S2 B), presumably

[Escribir texto] 
because more work has been expended in deforming the teeth during the lateral molar biting (Dumont et al. 2009). Overall, the pattern of strains experienced by the models is that all the dental cuspids (with the exception of the lingual ones of the Ea-model; see Fig. S2 B2) exhibit higher strains (see Fig. S3 B1, B3). Under this loading regime, the differences between models are not so substantial, probably because the different shape is not so decisive on the structural strength under lateral movements.

\section{Discussion}

\section{Dental changes related to increasing tooth crown height}

Overall, and from a structural perspective, the Cervus elaphus model seems to be more ideally suited under different loading regimes for concentrating stress flows (and also strains during normal occlusion) on few and small areas of contact, which is a consequence of its dental morphology. Essentially, this model is $(i)$ more elongated and narrower (Fig. 3 A), has (ii) more stylized and vertical (narrow-angled) cusps -cones and styles-, (iii) longer, sharper and higher buccal crests (Fig. 3 A1), and (iv) lingual crests that are more crescent-shaped (selenodont) (Fig. 3 A2) than the brachydont (Procervulus ginsburgi and Eotragus artenensis) models (Fig. 3 A3). Results are suggestive that these changes in morphology are associated with crown growth in the vertical plane, and are highly unlikely to be evolved in a low-crowned tooth. Because evolving hypsodonty requires extensive modification of skull structures to physically accommodate tall teeth (White 1959; Eronen et al. 2010), in a similar way the occlusal surface of the teeth could need also some modifications to accommodate a vertical growth. The most important aspect when Cervus is compared to a brachydont tooth is that the styles in the buccal wall of Cervus have increased their height more than the

[Escribir texto] 
cones (Fig. 3 B1 and B2), which results in an improved design where the edges of the crests are sharper and are closer together (Fig. 3 B3).

\section{Influence of tooth crown height on dental biomechanics and efficiency}

As hypsodont teeth exhibit changes not only in height, but also in both gross tooth shape and degree of selenodonty (as illustrated in Fig. 3), we conducted a comparative analysis to investigate the exclusive influence of hypsodonty on tooth biomechanics. We analyzed a new theoretical model (Pg-hypsodont model) that was digitally built from the original brachydont Pg-model, whose biomechanical behavior is known, with the aim of determining if an increase in crown height per se without any other morphological change entails an optimization for chewing. In accordance with our initial prediction and with the previous FE comparisons, it is expected that this new model behaves similarly to the Ce-model.

Although the new Pg-hypsodont and the Pg-model show somewhat similar qualitative patterns of stress (Fig. 2) and strain (see Fig. S3), they are quantitatively different in both simulations. Again, the von Mises stresses are mainly distributed in the central part of the buccal cones under vertically directed loads, and appear to be relatively faint (Fig. 2 A4). However, they withstand a higher mean stress (between $1.37 \times 10^{5}$ and $1.71 \times 10^{5} \mathrm{kPa}$ ) if compared to the value reached in the brachydont model. We also note that the patterns of stress are in no way comparable to those obtained for Ea- and Ce-models. More interestingly, the differences are particularly noticeable when compared with the latter, since the Pg-hypsodont model does not reduce the surface area involved in stress distribution. The analysis under grinding action still reveals larger differences between stress patterns of the original Pg-model and the modified one (Fig. 2 B4). Von Mises stresses are highest in the Pg-hypsodont model, and are not so 
concentrated on small areas of occlusion than would be expected according to the increase in height, thus indicating that it is the weaker of the two models under this loading condition. It seems therefore that the experimentally generated and higher model does not represent an improvement in terms of work efficiency, thus implying that increasing crown height per se does little. Indeed, under higher loads, it would fail first.

In addition, we found that it exhibits under both loading regimes a greater degree and more complicated pattern of strain than the others by having an increased proportion of tooth in projection (see Fig. S3 A4, B4), which does not lead to a biomechanical improvement. These results also failed to conclude that the Pg-hypsodont model is improved to the loading, since it is not effective in the concentration of strains.

This is unexpected, given the previous results, and poses a central question. If increasing dental crown height per se (without other associated changes in crown morphology) does appear to contribute to decrease the mechanical efficiency, then why have higher-crowned teeth been selected in the evolutionary history of deer?

\section{Hypsodonty: a mechanism for increasing the efficiency of chewing in ruminants}

FE modeling provides perspective for understanding how hypsodonty works within a biomechanical context for the first time. The most important aspect is that a jump in the mechanical efficiency exists between a brachydont tooth (Pg-model) and a significantly more hypsodont one (Ce-model), with a relatively high -though still brachydont- tooth (Ea-model) representing a transitional state. Thus, through FEA data, we can reveal that the concentration of stresses on the tooth becomes higher as the teeth become more hypsodont. Furthermore, hypsodonty in selenodont teeth enables stress to be restricted to those zones where loading as a consequence of chewing occurs. Since the tooth wear

[Escribir texto] 
is found in these areas, this fact therefore should be related to an improvement in the masticatory efficiency.

In this regard, we are aware that the analyses here presented are made using unworn molars, yet in practice this condition only exists for a period of the animal's life. However, it should be taken into account that here we analyze the general shape of the teeth, and more specifically the biomechanical response of the general dental design, and, accordingly, interpretations are not dependent of tooth wear. When the dentin emerges in a tooth, the biomechanics of the occlusal surface is different, thus appearing two enamel ridges that act by trapping the food between them (Lucas 2004). It must be stressed, however, that the dentin basins are exposed as a result of a considerable use, and the best design to chew any type of food is not due to such a detail, but indeed to the development of the crests and the elongated and conical shape of the cusps (as well as to cusps alignment), which is in fact what this study examines.

The effect of the aforementioned changes in the occlusal surface of teeth that are more hypsodont, such as those of C. elaphus (illustrated in Fig. 3), could be of a great functional relevance in more advanced wear states of the teeth. In particular, the smaller difference in height between the styles and the cones facilitates the progressive blunting of the cusps as the wear increases, a fact that also reduces the occlusal relief. According to dental mesowear, this morphology of the occlusal surfaces (blunt cusps) and type of relief (low) during wear are in fact related to grazing (Fortelius \& Solounias 2000).

As observed in our sample, an increase in tooth crown height by itself does not improve the mechanical efficiency of the chewing process. However, it does probably lead to a specific and pronounced variation in the dental morphology and the geometry of the occlusal surface (Fig. 3) that greatly enhances the mechanical behaviour of cervid teeth. It is possible therefore that the occlusal geometry is the trait under selection, and 
that the changes in crown height are merely a by-product born out of constraint for the aforementioned changes. These changes in dental shape of C. elaphus are also observed in middle Miocene mesodont bovids. Extant bovids, by contrast, are characterized by narrower teeth and early cusp fusion, and it is proposed that these are necessary morphological prerequisites for the development of higher molars in bovids (Heywood 2010). Without the ability to fuse cups early (Heywood 2010), cervids would need other significant changes (those here observed) in order to develop higher-crowned teeth. Although more empirical studies of hypsodont teeth are needed, data here presented can be used for better understanding the early development of hypsodonty. Our results provide therefore evidence to suggest that hypsodonty could be a necessary mechanism for building a new and more efficient occlusal geometry and can be considered to be an example of biomechanical optimization. In cervids, it may be the mechanism that leads to an increase in the mechanical efficiency by reducing the surface involved in stress distribution to only a few and small areas of contact (regions that are known in engineering as a "stress concentrators") to maximize the effectiveness of chewing.

\section{The evolution of "stress concentrators" higher cusps as mechanism for increasing the efficiency of chewing in grass-eating ruminants}

When food is within the mouth, what happens when teeth close down on other teeth with food in between mostly depends on the geometry of the teeth. It is well-known that the smaller an area is, the greater the pressure that is obtained for a given force or load. Therefore if the confinement in the area of the work surface of teeth results in an increase in the pressure produced during occlusion, then plant material would be more easily sectioned. It may be well to ask therefore whether the evolution of "stress

[Escribir texto] 
concentrators" higher cusps also could play a crucial role to increase the tooth efficiency in grazers.

Because ruminants, in contrast to non-ruminants, are less able to digest plant material directly, they are physiologically more limited by both the quantity of food that they can consume and the time spent in the process of chewing and digestion (Janis 1976;

Axmacher \& Hofmann 1988). For this reason, the higher effectiveness of the ruminant molar design must be addressed to increase the speed of chewing. Grazing ruminants eat higher fracture toughness, lower-quality and more fibrous foods than browsing ruminants (Lucas 2004; Heywood 2010; Codron et al. 2007). This diet also contains a high concentration of silica that, although should not be considered as a major abrasive agent of increased tooth wear (Sanson et al. 2007), reduces the ability of grazers to fracture and digest food (Robbins 1993). Therefore, a greater degree of efficiency in mastication is required. If the mechanical/physical properties of food determine the tooth shape required to divide it up (Lucas 2004), materials such as grass should be most efficiently reduced by a dentition with dental crests which act like shearing wedges (stress concentrators). This is exactly what happens in the higher-crowned teeth of Cervus elaphus. Studies about the resistance to mastication of different food items by specific dental types (Lucas 2004) point that foods with higher toughness, such as grass, require marginal ridges on the cusps so as to form wedges. When compared to browsing ruminants, grazers need to be able to take in larger quantities of food, and improve the process of chewing plus digestion in order to meet energy requirements. An increase in the abrasives in diet may not be important in increasing tooth wear (Sanson 2006). However, is more than likely that an increase in the average amount of food consumed plays a more critical role in tooth wear, and compensatory mechanisms (including changes in the occlusal surface) have been proposed to offset this wear (Pérez-Barbería

[Escribir texto] 
\& Gordon 1998). Hence, we interpret that there is a strong evolutionary imperative to make teeth hypsodont if the food is abundant, mechanically resistant (high toughness), fibrous and of a low-nutritive value, as this would be highly advantageous. In consequence, hypsodont-selenodont teeth would allow grazers to spend less time chewing, so giving more time for digestion, and/or would increase the volume of food ingested per unit of time.

\section{Conclusions}

Overall, and although more research is needed, our hypothesis is an argument in favor of the notion that the great increase in crown height during the Miocene is associated with an increase in grass foraging due to the tough nature and low-nutritional quality of grasses, rather than as a direct consequence of increasing demands for resisting the wear caused by grazing. Certainly, once hypsodonty was selected as the process that increases the efficiency of chewing, it would provide the additional advantage of maintaining a functional tooth in the face of intensive wear and prolong the life span of an animal, especially when ruminants incorporated the $\mathrm{C} 4$ grasses to their diets, since are mechanically more challenging to species than the C3 grasses (Wilson \& Hacker 1987) and show higher levels of fibre build up (Owen-Smith 1987).

As hypsodonty is recognized in several lineages with different physiological constraints, the morphological changes would be different for each of them but would depend on the biomechanical requirements of processing a great volume of food with low nutritive value. Therefore, it may be well to ask whether hypsodonty also played a crucial role in shaping the tooth morphology in other grazing mammal groups.

\section{Acknowledgements}

[Escribir texto] 
We thank the Centro Nacional de Investigación sobre la Evolución Humana (CENIEH)

for micro-CT scanning, and M. Antón for giving us permission to reproduce his

illustration of fossil taxa in supporting figure S1. Funding from this study came from the

Spanish Ministerio de Economía y Competitividad (projects CGL2010-216723,

CGL2010-19116 and CGL2011-25754, and JCI-2011-11697 to D.DM.), the Research

Group BSCH-UCM910607, and the government of Aragón (E05).

\section{References}

Anusavice, K.J. \& Tsai, Y.L. 1997: Stress distribution in ceramic crown forms as a function of thickness, elastic modulus, and supporting substrate. 264-267. In D. Bumgardner, D. \& Puckett A.D. (eds): Proceedings of the Sixteenth Southern Biomedical Engineering Conference. Biloxi, MS.

Axmacher, H. \& Hofmann, R.R. 1988:: Morphological characteristics of the masseter muscle of 22 ruminant species. Journal of Zoology 215, 463-473.

Azanza, B. 1993: Sur la nature des appendices frontaux des cervidés (Artiodactyla, Mammalia) du Miocène inférieur et moyen. Remarques sur leur systématique et leur phylogénie. Comptes Rendus de l'Académie des Sciences, Series II 316, 1163-1169.

Azanza, B. 2000: Cervidae (Artiodactyla, Mammalia) from the Miocene basins of Duero, Tajo, Calatayud-Teruel and Levante. Memorias del Museo Paleontológico de la Universidad de Zaragoza 8, 1-376. [In Spanish].

Codron, D., Lee-Thorp, J.A., Sponheimer, M. \& Codron, J. 2007: Nutritional content of savanna plant foods: implications for browse/grazer models of ungulate diversification. European Journal of Wildlife Research 53, 100-111.

[Escribir texto] 
Damuth, J. \& Janis, C.M. 2005: Paleoecological inferences using tooth wear rates, hypsodonty and life history in ungulates. Journal of Vertebrate Paleontology 25 (suppl), 49A.

DeMiguel, D., Fortelius, M., Azanza, B. \& Morales, J. 2008: Ancestral feeding state of ruminants reconsidered: earliest grazing adaptation claims a mixed condition for Cervidae. BMC Evolutionary Biology 8, 1-13.

DeMiguel, D., Azanza, B. \& Morales, J. 2010: Trophic flexibility within the oldest Cervidae lineage to persist through the Miocene Climatic Optimum. Palaeogeography, Palaeoclimatology, Palaeoecology 289, 81-92.

DeMiguel, D., Azanza, B. \& Morales, J. 2011: Paleoenvironments and paleoclimate of the Middle Miocene of central Spain: A reconstruction from dental wear of ruminants. Palaeogeography, Palaeoclimatology, Palaeoecology 302, 452-463.

DeMiguel, D., Quiralte, V., Azanza, B., Montoya, P. \& Morales, J. 2012: Dietary behaviour and competition for vegetal resources in two Early Miocene pecoran ruminants from Central Spain. Geodiversitas 34, 425-443.

Dumont, E.R., Grosse, I.R. \& Slater, G.J. 2009: Requirements for comparing the performance of finite element models of biological structures. Journal of Theoretical Biology 256, 96-103.

Eronen, J.T., Evans, A.R., Fortelius, M. \& Jernvall, J. 2010: The impact of regional climate on the evolution of mammals: a case study using fossil horses. Evolution 64 , $398-408$.

Fortelius, M. 1985: Ungulate cheek teeth: developmental, functional and evolutionary interrelations. Acta Zoologica Fennica 180, 1-76.

[Escribir texto] 
Fortelius, M. \& Solounias, N. 2000: Functional characterization of ungulate molars using the abrasion-attrition wear gradient: a new method for reconstructing paleodiets. American Museum Novitates 3301, 1-35.

Franz-Odendaal, T.A. \& Solounias, N. 2004: Comparative dietary evaluations of an extinct giraffid (Sivatherium hendeyi) (Mammalia, Giraffidae, Sivatherinae) from Langebaanweg, South Africa (early Pliocene). Geodiversitas 26, 675-685.

Gentry, AW. 2010: Bovidae. 741-796. In Werdelin, L. \& Sanders, W.J. (eds): Cenozoic mammals of Africa. Berkeley, University of California Press.

Hassanin, A. \& Douzery, E.J.P. 2003: Molecular and morphological phylogenies of Ruminantia and the alternative position of the Moschidae. Systematic Biology 52, $206-228$.

Hautier, L., Clavel, J., Lazzari, V., Gomes Rodrigues, H. \& Vianey- Liaud, M. 2010: Biomechanical changes and remodelling of the masticatory apparatus during mammalian evolution: the case of the Issiodoromyinae (Rodentia). Palaios 25, 6-13.

Heywood, J. 2010: Explaining patterns in modern ruminant diversity: contingency or constraint? Biological Journal of the Linnean Society 99, 657-672.

Janis, C.M. 1976: The evolutionary strategy of the Equidae and the origin of rumen and cecal digestion. Evolution 30, 757-774.

Janis, C.M. 1988: An estimation of tooth volume and hypsodonty indices in ungulate mammals, and the correlation of these factors with dietary preferences. Mémoirs de Musée d'Histoire naturelle, Paris (serie C) 53, 367-387.

Janis, C.M. \& Fortelius, M. 1988: On the means whereby mammals achieve increased functional durability of their dentitions, with special reference to limiting factors. Biology Reviews 63, 197-230.

[Escribir texto] 
Jardine, P.E., Janis, C.M., Sahney, S. \& Benton, M.J. 2012: Grit not grass: Concordant patterns of early origin of hypsodonty in Great Plains ungulates and Glires. Palaeogeography, Palaeoclimatology, Palaeoecology 365-366, 1-10.

Jordana, X., Marín-Moratalla, N., DeMiguel, D., Kaiser, T.M. \& Köhler, M. 2012:

Evidence of correlated evolution of hypsodonty and exceptional longevity in endemic insular mammals. Proceedings of the Royal Society B 279, 3339-3346.

Kupczik, K. et al. 2007: Assessing mechanical function of the zygomatic region in macaques: validation and sensitivity testing of finite element models. Journal of Anatomy 210, 41-53.

Lin, C.P. \& Douglas, W.H. 1994: Structure-property relations and crack resistance at the bovine dentin-enamel junction. Journal of Dental Research 73, 1072-1078.

Lucas, P.W. 2004: Dental functional morphology. Cambridge, UK, Cambridge University Press.

Lucas, P.W., Turner, I.M., Dominy, N.J. \& Yamashita, N. 2000: Mechanical defenses to herbivory. Annals of Botany 86, 913-920.

MacFadden, B.J. 1997: Origin and evolution of the grazing guild in New World terrestrial mammals. Trends in Ecology \& Evolution 12, 182-187.

MacFadden, B.J. 2000: Origin and evolution of the grazing guild in Cenozoic New World terrestrial mammals. 223-244. In Sues, H.-D. (ed): Evolution of Herbivory in Terrestrial Vertebrates. Cambridge, UK, Cambridge University Press.

MacFadden, B.J. \& Cerling, T.E. 1994: Fossil horses, carbon isotopes and global change. Trends in Ecology \& Evolution 9, 481-486.

Maddison, D.R. \& Maddison, W.P. 2003: MacClade 4.06 Sinauer Associates, Sunderland, Massachusetts.

[Escribir texto] 
McNaughton, S.J., Tarrants, J.L., McNaughton, M.M. \& Davis, R.D. 1985: Silica as a defense against herbivory and a growth promotor in African grasses. Ecology 66, $528-535$.

Mendoza, M. \& Palmqvist, P. 2007: Hypsodonty in ungulates: an adaptation for grass consumption or for foraging in open habitat? Journal of Zoology 274, 134-142.

Mihlbachler, M.C. \& Solounias, N. 2006: Coevolution of tooth crown height and diet in oreodonts (Merycoidodontidae, Artiodactyla, Mammalia) examined with phylogenetically independent contrasts. Journal of Mammalian Evolution 13, 11-36.

Mihlbachler, M.C., Rivals, F., Solounias, N. \& Semprebon, G.M. 2011: Dietary change and evolution of horses in North America. Science 331, 1178-1181.

Osborn, H.F. 1910: The Age of Mammals in Europe, Asia and North America. New York, MacMillan.

Owen-Smith, N. 1987: Pleistocene extinctions: the pivotal role of megaherbivores. Paleobiology 13, 351-362.

Pérez-Barbería, F.J. \& Gordon, I.J. 1998: The influence of molar occlusal surface area on the voluntary intake, digestion, chewing behaviour and diet selection of red deer (Cervus elaphus). Journal of Zoology 245, 307-316.

Rayfield, E.J. 2007: Finite element analysis and understanding the biomechanics and evolution of living and fossil organisms. Annual Review of Earth and Planetary Sciences 35, 541-576.

Rayfield, E.J. et al. 2001: Cranial design and function in a large theropod dinosaur. Nature 409, 1033-1037.

Richmond, B.G. et al. 2005: Finite element analysis in functional morphology. Anatomical Record 283A, 259-274.

[Escribir texto] 
Rivals, F. \& Semprebon, G.M. 2006: A comparison of the dietary habits of a large sample of the Pleistocene pronghorn Stockoceros onusrosagris from the Papago Springs Cave in Arizona to the modern Antilocapra americana. Journal of Vertebrate Paleontology 26, 495-500.

Robbins, C.T. 1993: Wildlife Feeding and Nutrition. New York: Academic Press.

Ross, C.F. 2005: Finite element analysis in vertebrate biomechanics. Anatomical Record 283A, 253-258.

Sanson, G.D. 2006: The biomechanics of browsing and grazing. American Journal of Botany 93, 1531-1545.

Sanson, G.D., Kerr, S.A. \& Gross, K.A. 2007: Do silica phytoliths really wear mammalian teeth? Journal of Archaeological Science 34, 526-531.

Semprebon, G., Janis, C.M. \& Solounias, N. 2004: The diets of the Dromomerycidae (Mammalia: Artiodactyla) and their response to Miocene vegetational change. Journal of Vertebrate Paleontology 24, 427-444.

Simpson, G.G. 1944: Tempo and Mode in Evolution. New York, Columbia University Press.

Simpson, G.G. 1953: The Major Features of Evolution. New York, Columbia University Press.

Solounias, N. \& Moelleken, S.M.C. 1994: Differences in diet between two archaic ruminant species from Sansan, France. Historical Biology 7, 203-220.

Stirton, R.A. 1947: Observation of evolutionary rates in hypsodonty. Evolution 1, 32 51.

Strait, D.S. et al. 2010: The structural rigidity of the cranium of Australopithecus africanus: implications for diet, dietary adaptations, and the allometry of feeding biomechanics. Anatomical Record 293, 583-593.

[Escribir texto] 
Strömberg, C.A. 2006: Evolution of hypsodonty in equids: testing a hypothesis of adaptation. Paleobiology 32, 236-258.

Thomason, J.J. 1991: Cranial strength in relation to estimated biting forces in some mammals. Canadian Journal of Zoology 69, 2326-2333.

Ungar P.S. et al. 2012: Early Neogene environments in East Africa: Evidence from dental microwear of tragulids. Palaeogeography, Palaeoclimatology, Palaeoecology 342-343, 84-96.

White, T.E. 1959: The endocrine glands and evolution. Os cementum, hypsodonty, and diet. Contributions from the Museum of Paleontology. University of Michigan 13, $211-265$.

Williams, S.H. \& Kay, R.F. 2001: A Comparative Test of Adaptive Explanations for Hypsodonty in Ungulates and Rodents. Journal of Mammalian Evolution 8, 207229.

Wilson, J.R. \& Hacker, J.B. 1987: Comparative digestibility and anatomy of some sympatric C3 and C4 arid zone grasses. Australian Journal of Agricultural Research $38,287-295$.

Wroe, S., Clausen, P. Mchenry, C. Moreno, K. \& Cunningham, E. 2007: Computer simulation of feeding behavior in the thylacine and dingo as a novel test for convergence and niche overlap. Proceedings of the Royal Society B 274, 2819-2828.

Zienkiewicz, O.C. \& Cheung, Y.K. 1967: The Finite Element Method and Structural and Continuum Mechanics. London, McGraw-Hill.

Zienkiewicz, O.C. 1971: The Finite Element Method in Engineering Science. London, McGraw-Hill.

\section{Figure Captions}

[Escribir texto] 
Fig. 1. Relationship between hypsodonty index and diet. (A) Bivariate plot of feeding behaviour against hypsodonty index for living (black symbols) and extinct (solid symbols) ruminants. Abbreviations; B, browsers; B-D, browse-dominated mixed feeders; M, mixed feeders; G-D, grass-dominated mixed feeders and G, grazers. (B) Evolutionary reconstruction of hypsodonty (left) and feeding style (right) in Ruminantia. Characters traced onto a tree topology based on the molecular phylogeny (Hassanin \& Douzery 2003) using MacClade 4.06 (Maddison \& Maddison 2003) showing all most parsimonious state at each node. Dicrocerus and Procervulus were included in the cladogram as stem representative of extant cervids (Azanza 1993, 2000), while Eotragus was included as stem representative of extant bovids (Gentry 2010). Other basal extinct taxa were also included in the cladogram to obtain more reliable ancestral characters. Grey arrows indicating cases in which the development of hypsodonty does not show correspondence with the acquisition of grazing habits. Data of living ruminants from Janis (1988) and Fortelius \& Solounias (2000). Data of extinct species from Solounias \& Moelleken (1994), Rivals \& Semprebon (2006) and DeMiguel et al. (2008, 2010, 2012).

Fig. 2. von Mises stress in the finite element models under different conditions. von Mises stress (a good predictor of failure under ductile fracture) during normal occlusion (A) and grinding action - lateral movements - (B) while chewing on the molars of fossil Procervulus ginsburgi (1; Pg-model) and Eotragus artenensis (2; Ea-model); living Cervus elaphus (3; Ce-model); and on a theoretical hypsodont model (4; Pg-hypsodont model). In mechanical terms, the application of a load results in stresses that are defined as force per unit area and are a measure used to describe the internal forces in a structure. Warm colors indicate high stress and cool colors indicate regions of low

[Escribir texto] 
stress. Circles showing patterns after homogenizing results according to the same stress scale (von Mises: min. 0 and $\max .2 .00 \times 10^{6}$ ).

Fig. 3. Morphological innovations in an improved non-brachydont and selenodont tooth. (A) In addition to the apparent increase in height and length, and the decrease in width, dental innovations comprise more crescent-shaped (selenodont) and curvaceous lingual crests (1) compared to those of a brachydont tooth (2), and also longer and higher buccal crests (3). (B) Differences in crest morphology (P; proximal and D; distal edges) and height of the styles $(\mathrm{H})$ in relation to the height of the cones between a more hypsodont tooth (Ce-model) and a brachydont (Pg-model) one. From an evolutionary perspective, styles have experienced an increase in height in the former B1) when compared to those of the latter (2), and are closer to the cone apices. The result is a new design in Ce-model -in where the edges of the crests are sharper and closer together (3), tuned for reducing the surface involved in chewing to only a few and small areas.

[Escribir texto] 
(A)

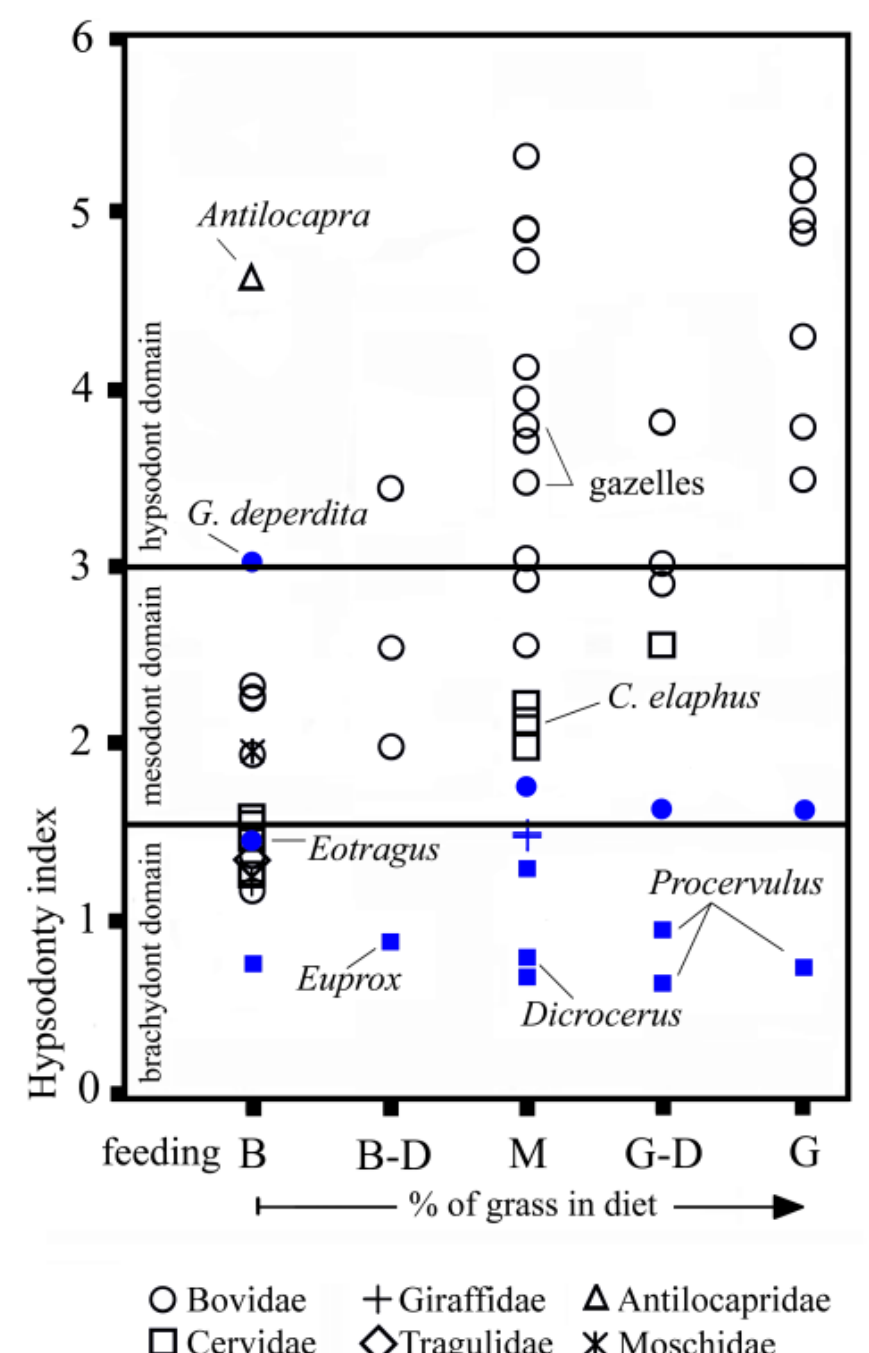

(B)

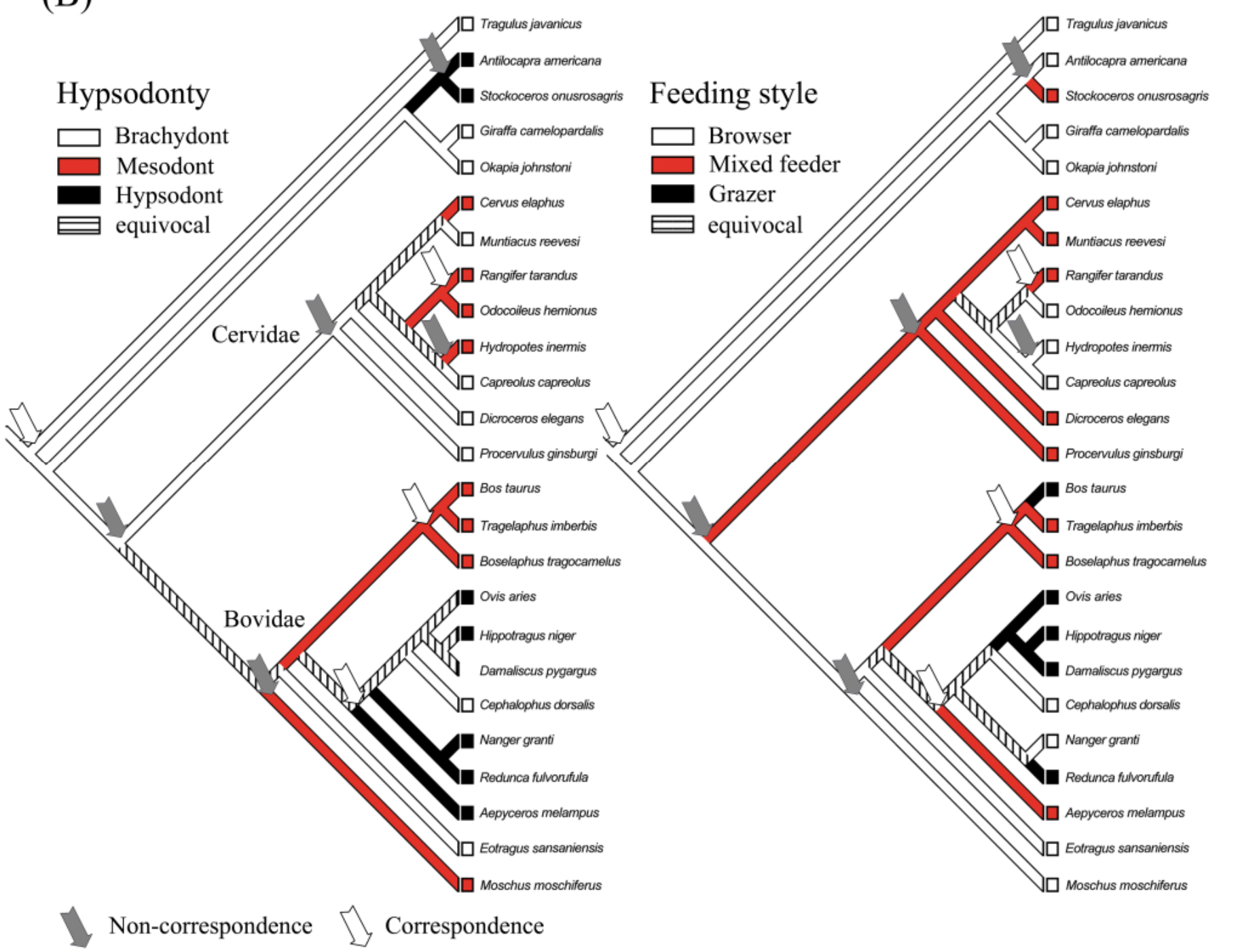




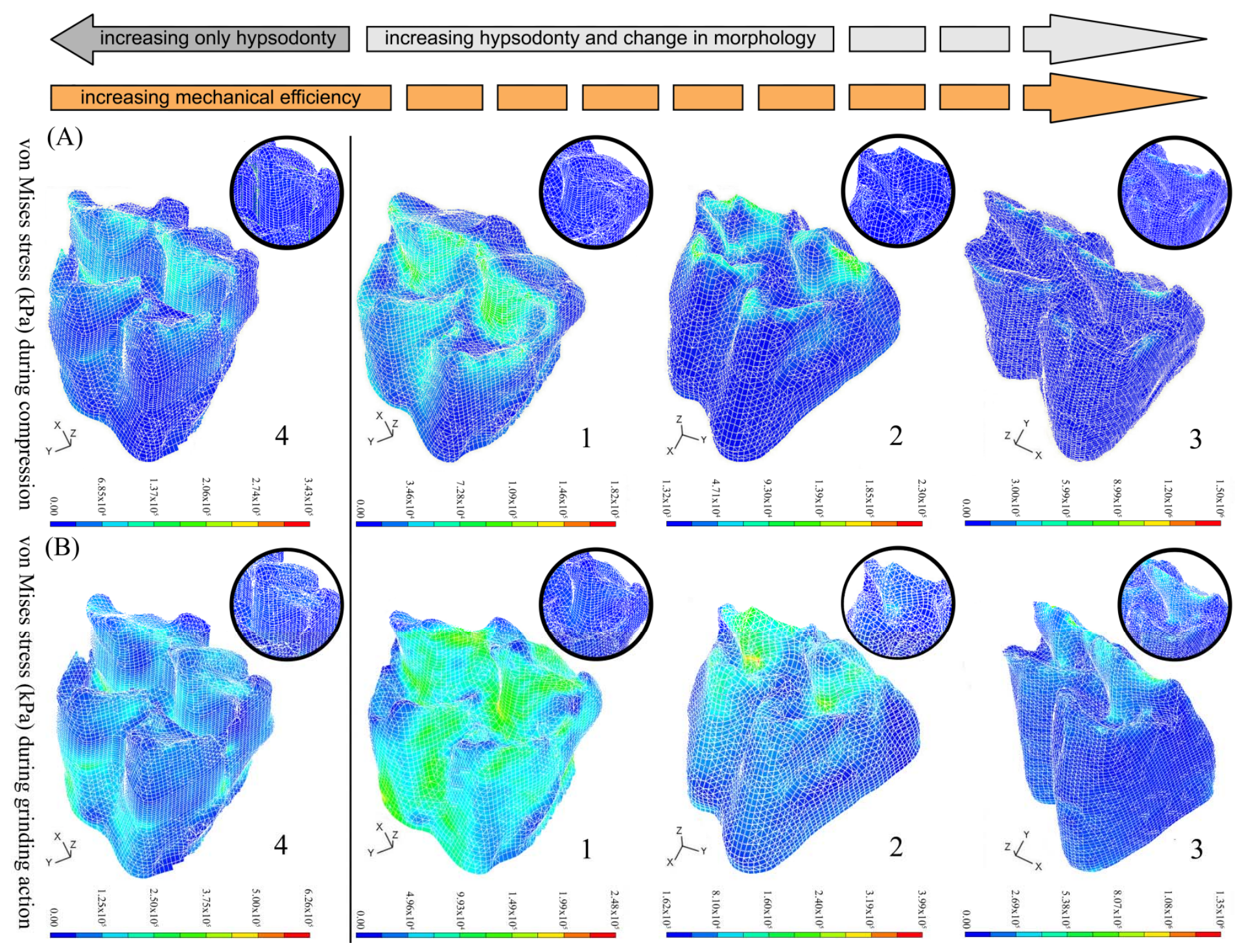


(A)

1 Longer and higher buccal crests

(B)

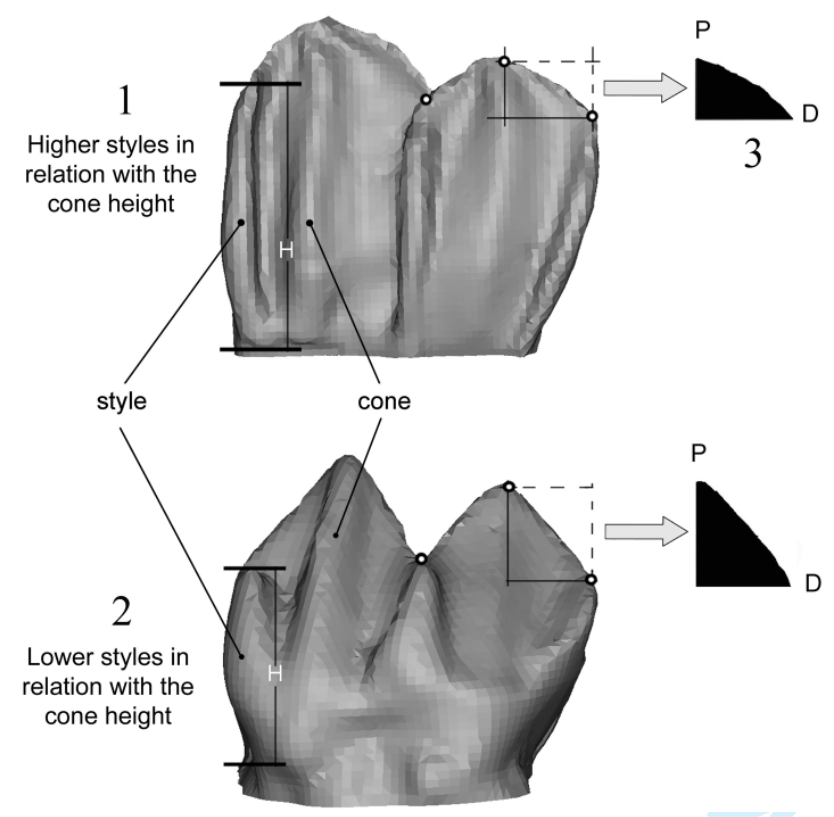


Supporting Information: DeMiguel et al.

On the association between increased tooth crown-height and chewing efficiency, and implications for Cervidae evolution

Supporting Introduction

Supporting Figures S1-S3

Supporting References

\section{Supporting Introduction}

Hypsodonty. In general terms, hypsodonty describes the specific feature of those mammals whose dental crowns are high; the higher the crown of the tooth is, the more hypsodont the animal. Accordingly, teeth are readily categorized in increasing order of height as brachydont (a primitive condition), mesodont, and hypsodont (a derived condition), and although hypsodonty is fundamentally used as a relative term (e.g., teeth of American bison Bison bison are more hypsodont than those of moose Alces alces), different measures have been proposed to its quantitative analysis (Van Valen 1960; Janis 1988).

\section{Inconsistencies and incongruities for explaining the increase of tooth crown height.}

Several inconsistencies and incongruities currently exist regarding the hypotheses that try to explain the origin and evolution of hypsodonty. Firstly, the premise that silica of many grasses is harder than enamel and causes tooth wear has been widely accepted and often cited in literature, but almost all citations refer to a single study (Baker et al. 1959). Silica exists in a number of different states of different hardness (from classic quartz, opal or silica gel, to water glass) of which only the former can be harder than teeth. Hardness of silica certainly helps a plant to deter specific predators, but it is still 
unknown if these particles really wear teeth of large mammalian herbivores. Recent data claim therefore that phytoliths should not be considered as a major source of tooth wear (Sanson 2006; Sanson et al. 2007). It may appear logical to suppose that silica agents could be more essential for lending the plant structural rigidity (Kaufman et al. 1979) than for avoiding herbivory, especially if taking into account the current predominance of grazers in today's ecosystems. The importance of exogenous abrasives in favoring tooth wear has been also debated (White 1959; Webb 1977, 1983; MacFadden 1997; Mendoza \& Palmqvist 2007), and it is argued that dust and grit of dry ecosystems was not a primary selective factor in determining tooth height because not all hypsodont fossil equids are found in the same sedimentary environments (MacFadden \& Cerling 1994). Finally, and although it is also hypothesized that having a low nutritional and fibrous diet of grass might require an increase in total masticatory effort to fracture foods, and hence a high rate of tooth wear, it is not at all clear that specialized grazing ungulates have to produce higher chewing pressures (Axmacher \& Hofmann 1988). 


\section{Supporting Figures}

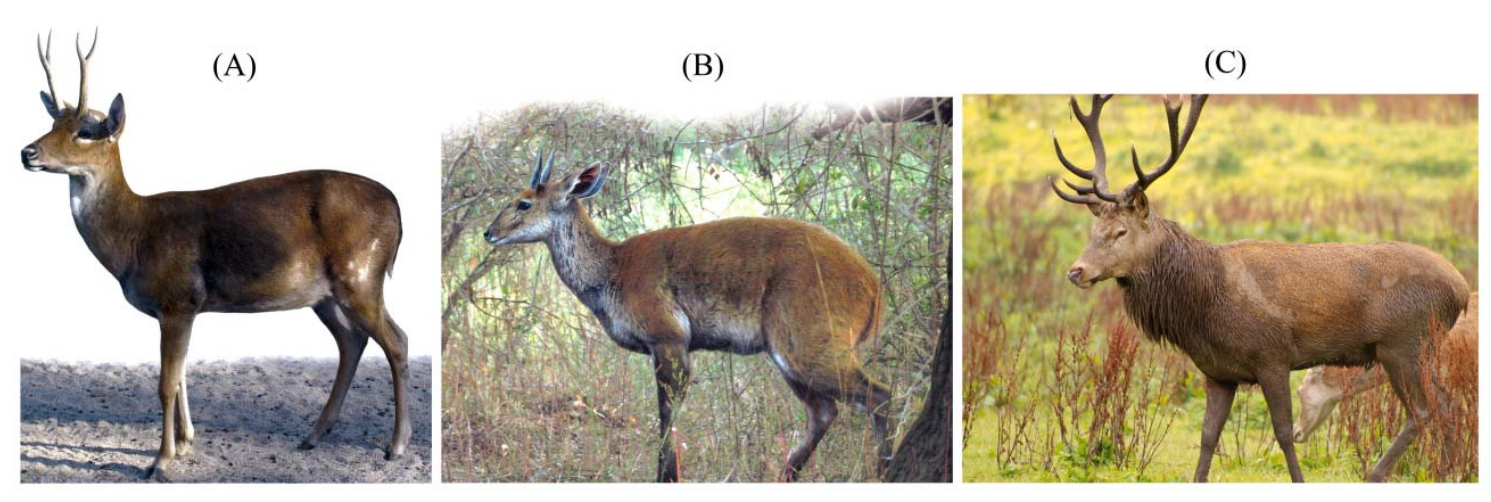

Fig. S1. Life reconstruction of the studied taxa. Fossil (A) Procervulus and (B)

Eotragus. Artwork by Mauricio Antón. (C) Picture of an adult male of extant Cervus elaphus. 


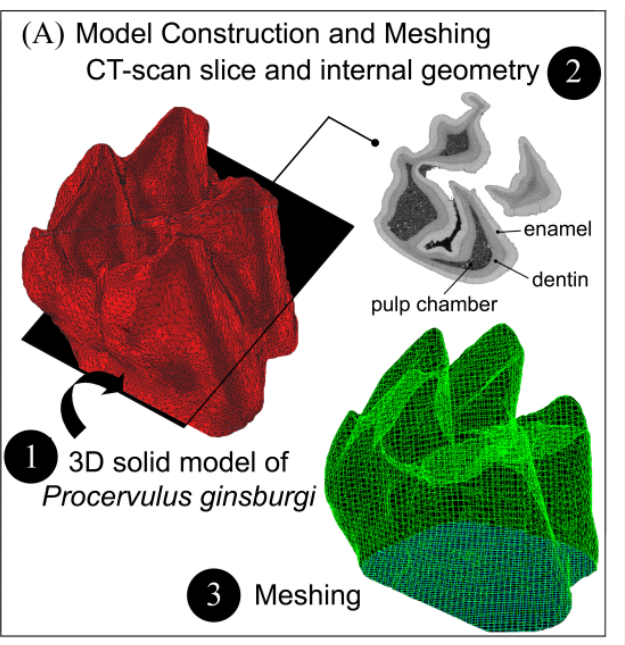

(B) Boundary Condition Assignment
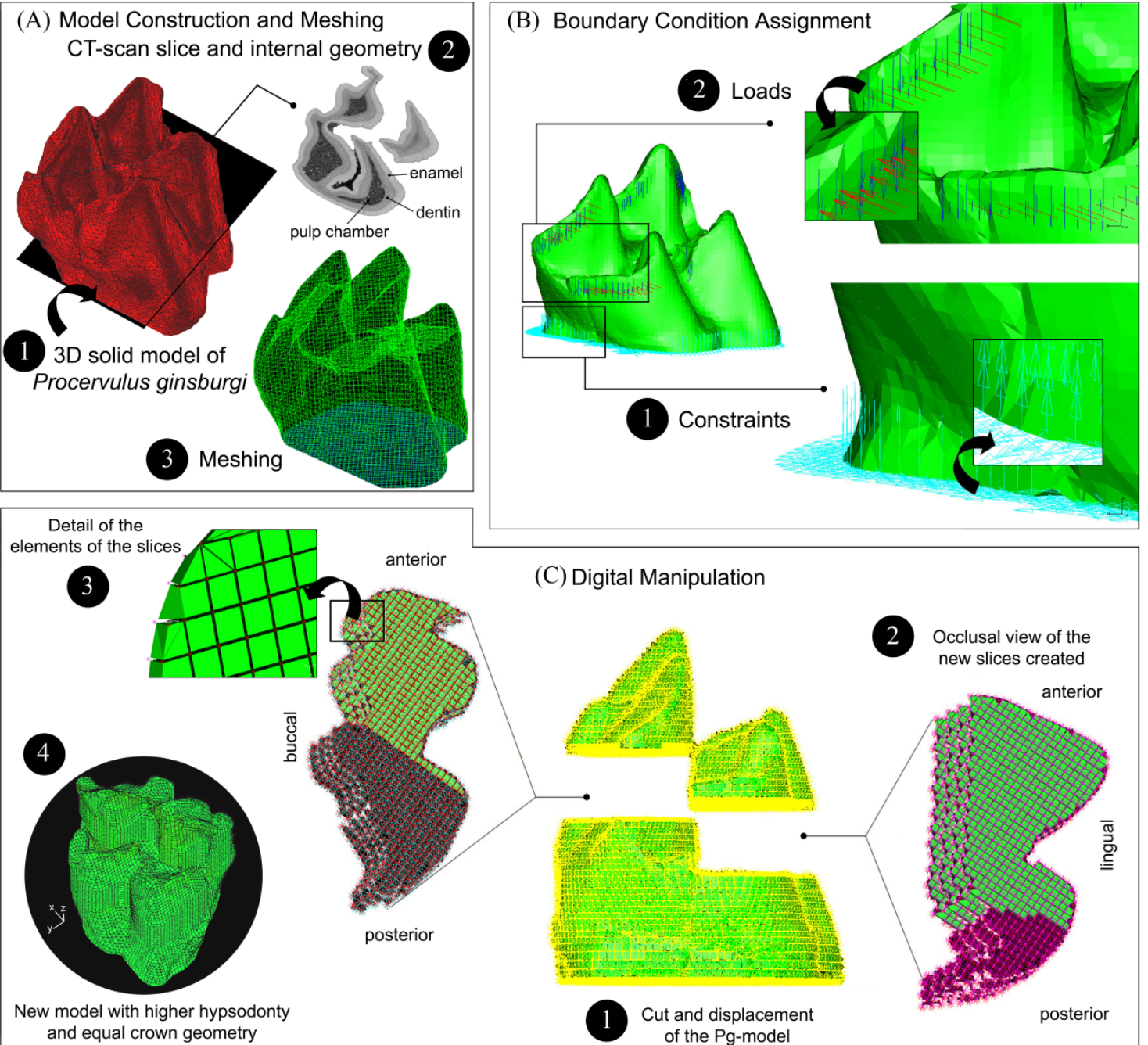

(C) Digital Manipulation

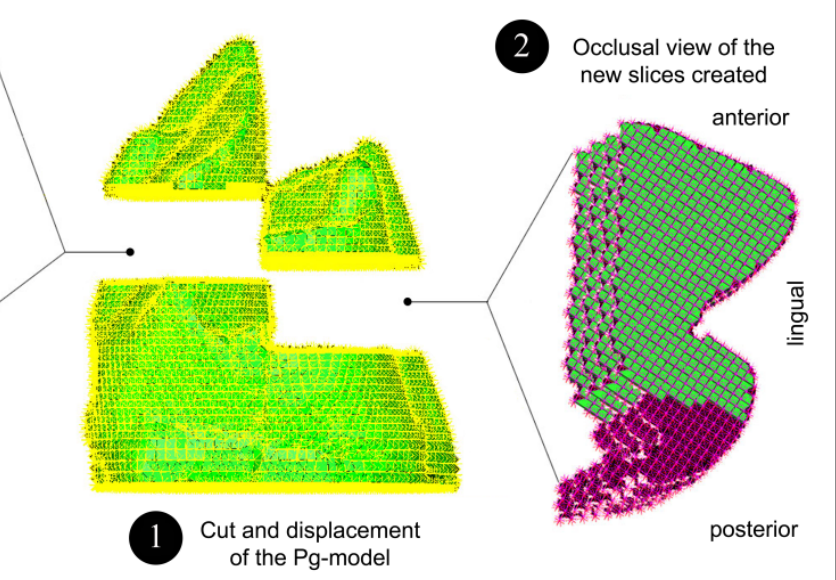

Fig. S2. Stepwise description of finite element analysis. (A) 3D Model Construction and Meshing: White Light Scanning was used as the basis for creating solid models (1) in a Computer-Assisted-Design (CAD) software package while information obtained from Computed Tomography (CT) scans through micro-CT slice images (2) were used to capture the three main layers of each tooth (enamel, dentin and pulp chamber). CT scanning was conducted at the Centro Nacional de Investigación sobre la Evolución Humana (CENIEH), in Burgos (Spain), using a $\mu$ CT 80 (Scanco Medical) which is ideal for scanning teeth with high resolution. The solid models were converted into finite element meshes (3) in ABAQUS software. (B) Boundary Condition Assignment: Regarding constraint conditions (1), each model was constrained from rigid motion by fixing a plane of nodes just below the crown that represents the contacts between the 
tooth crown and the maxillar (1; light blue arrows). In order to recreate the ruminant mastication kinetics and simulate the contact between the upper second molar and the food item (2), we made a first analysis by creating compressive (vertically) oriented forces which represent the forces acting during the bite movement (2; dark blue arrows). Then, a second analysis was conducted by generating lateral (horizontally) oriented forces which represent the forces acting during the lateral movement of the jaws to crush and grind (2; red arrows). (C) Digital Manipulation: We cut and displaced the original Pg-model through a surface far away enough from the cusps and the occlusal surface to maintain its dental details (1), and consecutive slices were then manually generated according to the original shape of the tooth and added inside (2). Volumes of the new slices were meshed creating solid tetrahedral, hexahedral, and three-sided elements (3). This procedure allowed us to create a new theoretical model with higher height of the body tooth and without causing variation in the occlusal surface geometry (4). Von Mises and deformation were calculated for this model and results compared between models. 

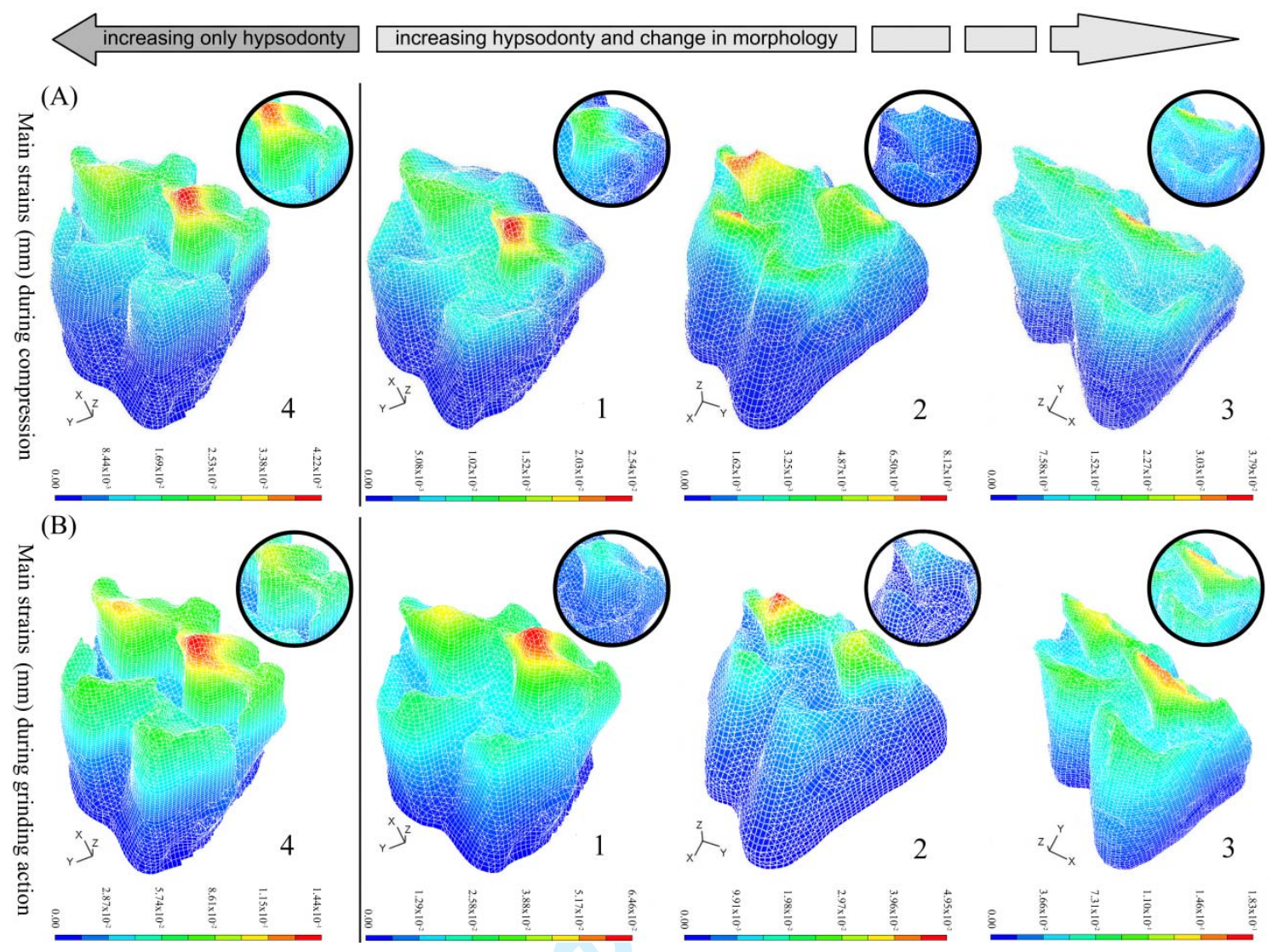

Fig. S3. Patterns of strains in the finite element models under different conditions.

Strains during normal occlusion (A) and grinding action—-lateral movements-(B)

while chewing on the molars of fossil Procervulus ginsburgi (1; Pg-model) and

Eotragus artenensis (2; Ea-model); living Cervus elaphus (3; Ce-model); and on a theoretical hypsodont model (4; Pg-hypsodont model). In mechanical terms, strain describes the deformations that result from an imposed load and is defined as the change in length divided by original length. Circles showing patterns after homogenizing results according to the same stress scale (deformation: min. 0 and max. $\left.4.50 \times 10^{-2}\right)$. 


\section{Supporting References}

Axmacher, H. \& Hofmann, R.R. 1988: Morphological characteristics of the masseter muscle of 22 ruminant species. Journal of Zoology 215, 463-473.

Baker, G., Jones, L.H.P. \& Wardrop, I.D. 1959: Cause of wear in sheep’s teeth. Nature 184, 1583-1584.

Janis, C.M. 1988: An estimation of tooth volume and hypsodonty indices in ungulate mammals, and the correlation of these factors with dietary preferences. Mémoirs de Musée d'Histoire naturelle, Paris (serie C) 53, 367-387.

Kaufman P.B. et al. 1979: Studies on silica deposition in sugarcane (Saccharum spp.) using scanning electron microscopy, energy dispersive X-ray analysis, neutron activation analysis, and light microscopy. Phytomorphology 29, 185-193.

MacFadden, B. J. 1997: Origin and evolution of the grazing guild in New World terrestrial mammals. Trends in Ecology \& Evolution 12, 182-187.

MacFadden, B.J. \& Cerling, T.E. 1994: Fossil horses, carbon isotopes and global change. Trends in Ecology \& Evolution 9, 481-486.

Mendoza, M. \& Palmqvist, P. 2007: Hypsodonty in ungulates: an adaptation for grass consumption or for foraging in open habitat? Journal of Zoology 274, 134-142.

Sanson, G.D. 2006: The biomechanics of browsing and grazing. American Journal of Botany 93, 1531-1545.

Sanson, G.D., Kerr, S.A. \& Gross, K.A. 2007: Do silica phytoliths really wear mammalian teeth? Journal of Archaeological Science 34, 526-531.

Van Valen, L. 1960: A functional index of hypsodonty. Evolution 14, 531-532.

Webb, S. D. 1977: A history of savanna vertebrates in the New World. Part I: North America. Annual Review of Ecology and Systematics 8, 355-380. 
Webb, S.D. 1983: The rise and fall of the Late Miocene ungulate fauna in North America. 267-306. In Nitecki, M.H. (ed): Coevolution. Chicago, University of Chicago Press.

White, T.E. 1959: The endocrine glands and evolution. Os cementum, hypsodonty, and diet. Contributions from the Museum of Paleontology. University of Michigan 13, 211-265. 